\title{
O LÚDICO E OS CONTEÚDOS MATEMÁTICOS: REVISÃO DO CONTEÚDO DE POTENCIAÇÃO POR MEIO DE OFICINAS DE JOGOS PEDAGÓGICOS
}

\author{
Thamires Belo de Jesus ${ }^{1}$
}

\author{
Instituto Federal do Espírito Santo \\ Campus Cachoeiro de Itapemirim - Rodovia Cachoeiro x Alegre, BR-482, Km 05, Morro Grande, Caixa \\ Postal 527, Cachoeiro de Itapemirim-ES, CEP 29300-970.
}

\section{RESUMO}

Este trabalho relata uma experiência realizada durante as aulas de revisão que antecederam a avaliação trimestral de matemática dos alunos do $7^{0}$ ano do ensino fundamental do Colégio Nacional, localizado em Vitória - ES. O objetivo desta experiência foi realizar a revisão do conteúdo de potenciação por meio de oficinas de jogos. Estas oficinas foram realizadas durante duas aulas de 50 minutos, com atividades aplicadas de forma individual e em grupo. Foram utilizados os seguintes jogos: bingo da potenciação, baralho das potenciações e expressões numéricas e o jogo da memória. Os jogos foram confeccionados com materiais reutilizáveis, papelão e folhas de rascunho. 0 resultado da avaliação foi analisado e utilizado como base para avaliação das oficinas realizadas. A realização destas oficinas mostrou as diferentes possibilidades de inserção de jogos como recursos pedagógicos para o ensino e aprendizagem de matemática, especificamente, nas aulas revisão de conteúdos.

Palavras-chave: potenciação, jogos pedagógicos, processo de ensino-aprendizagem.

\begin{abstract}
This paper reports an experiment conducted during the review classes prior to the quarterly review of mathematics of the 7th year of elementary school at the school located in Vitoria of Espírito Santo State. The objective of this experiment was to perform a review of the contents of empowerment through workshops games. These workshops were held for two 50-minute lessons, with activities applied individually and in groups. These games were used: Bingo of potentiation, deck, numeric expressions and memory game. The games were made with reusable materials, cardboard and sheets of draft. The evaluation result was analyzed and used as a basis for evaluation of workshops. The completion of these workshops showed the different possibilities of entering games as educational resources for teaching and learning mathematics, specifically in class review contents.
\end{abstract}

Keywords: potentiation, pedagogic games, teaching and learning process.

\footnotetext{
${ }_{1}^{1}$ Professora de Matemática, Mestre em Educação em Ciências e Matemática, Instituto Federal do Espírito Santo Campus Cachoeiro de Itapemirim. Email: thamiresbelo@yahoo.com.br
} 


\section{INTRODUÇÃO}

A disciplina de matemática é vista na sala de aula como algo quase "inacessível", difícil de ser entendida. Muitos alunos vivem queixando-se sobre a aplicação da matemática e como podem aprendê-la de forma mais prazerosa. Este é um dos desafios dos professores que lecionam a disciplina de matemática, torná-la mais compreensível e acessível a todos os alunos.

Em face desta necessidade diária de problematização, contextualização e validação dos conteúdos, especificamente dos conteúdos de potenciação, foi elaborado uma oficina de jogos com o objetivo de revisar esses conteúdos que posteriormente foram avaliados no teste trimestral. Esta estratégia de utilizar os jogos no ensino de matemática é muito eficaz, se trabalhado de forma compartilhada e embasada pelos conteúdos, uma vez que, o jogo, segundo Piaget (1984, p. 44), "é formado por um conjunto linguístico que funciona dentro de um contexto social; possui um sistema de regras e se constitui de um objeto simbólico que designa também um fenômeno". Estes jogos podem proporcionar conforme Rego (2000, p.79) "ambientes desafiadores, capazes de estimular o intelecto proporcionando a conquista de estágios mais elevados do raciocínio". Estes ambientes desafiadores, por sua vez, podem levar a um maior estímulo para a aprendizagem dos conteúdos matemáticos.

Com base nos referenciais teóricos que estimulam uso de jogos correlacionados com os conteúdos, foi elaborada uma oficina de jogos matemáticos focados na potenciação, como forma de revisar os conteúdos e preparar os alunos para a avaliação. Este último ponto, a avaliação trimestral, foi uma etapa de grande importância para a análise da experiência realizada, uma vez que, segundo Rosa Neto (1992, p. 41):

Avaliar não significa constatar o que ocorreu, mas fazer um balanço entre o que se pretendia e o que foi conseguido. É algo que compromete muito o educador, mas também é o único instrumento capaz de apontar em que direção e com que intensidade caminha o desenvolvimento do aluno.

O objetivo deste trabalho foi analisar oficinas de matemática usando diferentes possibilidades de inserção jogos pedagógicos como recursos didáticos no ensino e aprendizagem de matemática, especificamente, nas aulas de revisão do conteúdo de potenciação. 


\section{PROCEDIMENTOS METODOLÓGICOS}

Esta oficina de jogos matemáticos, com foco na potenciação, foi realizada nas duas últimas aulas que antecederam a avaliação trimestral dos alunos do $7^{0} \underline{a}$ ano do ensino fundamental do Colégio Nacional. A turma era bem heterogênea e composta por 25 alunos, alguns alunos com bastante dificuldade e outros com muita facilidade de trabalhar os conceitos matemáticos. Estas oficinas foram realizadas durante duas aulas de 50 minutos, e as atividades foram realizadas de forma individual e em grupo. Foram utilizados os seguintes jogos: bingo da potenciação, baralho das potenciações e expressões numéricas e o jogo da memória. A escolha dos jogos e suas respectivas regras foram avaliadas conforme as dúvidas dos alunos, com o objetivo que trabalhar exatamente os pontos de maiores importâncias e dificuldades apresentadas pelo conjunto.

Na primeira aula foram utilizados o bingo da potenciação e o jogo da memória. No primeiro jogo os alunos receberam uma cartela contendo resultados de potências; eu sorteava as operações e estipulava um tempo para que os alunos realizassem os cálculos e marcassem o resultado, caso estivesse presente na cartela. 0 aluno ganhador foi aquele que primeiro preencheu toda a cartela. O segundo jogo consistia em dez cartelas com operações e resultados envolvendo os conteúdos da prova. Esta atividade foi realizada em dupla e o objetivo foi trabalhar a capacidade de calcular as multiplicações indicadas em cada conjunto base-expoente e encontrar a potência indicada em outra carta; os alunos foram dispostos em duplas para facilitar os cálculos e a busca do par correto para cada carta. Os pontos eram computados não só pelos números de erros e acertos, mas também pelo tempo e no final ganhava a dupla que conseguisse o maior número de pontos. No jogo da memória, foram utilizadas as cartas do baralho da potenciação e foram utilizadas as regras próprias do jogo da memória.

No segundo dia de oficinas, estava planejada a realização apenas do jogo do baralho das potências e expressões numéricas, porém a pedido dos alunos foi realizado novamente o bingo da potenciação. 0 jogo do baralho é semelhante a um baralho convencional, porém no lugar dos "naipes" existiam expressões envolvendo potências e os seus respectivos resultados. Este jogo era disputado com quatro alunos que formavam duplas, os vencedores eram os alunos que, ao final do jogo, estavam com o maior número de cartas corretas; para evitar que os alunos efetuassem jogadas sem a total certeza, foi estabelecido como regra que a cada erro 
a dupla perderia um ponto. Com isso os alunos passaram a usar o caderno para efetuar as expressões de forma correta e depois realizavam as jogadas.

O interessante disso tudo é que os próprios alunos estabeleceram a estratégia de utilizar o caderno para registar as operações, assim de certa forma estavam revisando os conteúdos da prova. Após a realização das oficinais foi aplicada a avaliação trimestral em que os resultados foram utilizados para a avaliação não só dos alunos, mas também das oficinais realizadas, uma vez que, estas fizeram parte das aulas em que os conteúdos foram trabalhados.

\section{RESULTADO E DISCUSSÃO}

Na oficina do bingo da potenciação, foram abordados os conceitos da potenciação e o cálculo mental de algumas potências. As peças de sorteio e respectivas cartelas foram confeccionadas com base nas potências vistas com maior dificuldade pelos alunos. Para evitar que algum aluno marcasse os números sem ter a certeza que este havia sido "cantado" eu confeccionei uma cartela com todos os resultados das operações a serem sorteadas, e desta forma, a cada número sorteado eu marcava na cartela de soluções.

Assim quando um aluno "cantava bingo" eu fazia a verificação dos números marcados e só depois ditava o campeão. Durante a realização do bingo alguns alunos cantavam bingo, porém ao corrigir as cartelas eu verifiquei que alguns números estavam marcados de forma incorreta. 0 aluno que marcava errado devia fazer no caderno as operações que havia marcado incorretamente na cartela. Seguem nas Figuras 1 e 2 exemplos das peças produzidas para o bingo e um modelo de tabela utilizada pelos alunos.

Durante a realização desta atividade percebi que os alunos procuravam se concentrar ao máximo para encontrar o resultado correto e buscar a vitória na competição. Alguns alunos disseram durante e pós-atividade que daquela forma era mais fácil aprender a potenciação, pois eles estavam usando os cálculos para um fim específico que era ganhar a disputa do bingo. Essas falas estavam presentes durante todas as oficinas. Para estimular a participação de todos os alunos nas oficinas, estes estavam sendo avaliados conforme a participação nas atividades. E especificamente para o bingo foi utilizado chocolates como prêmio para os vencedores. 


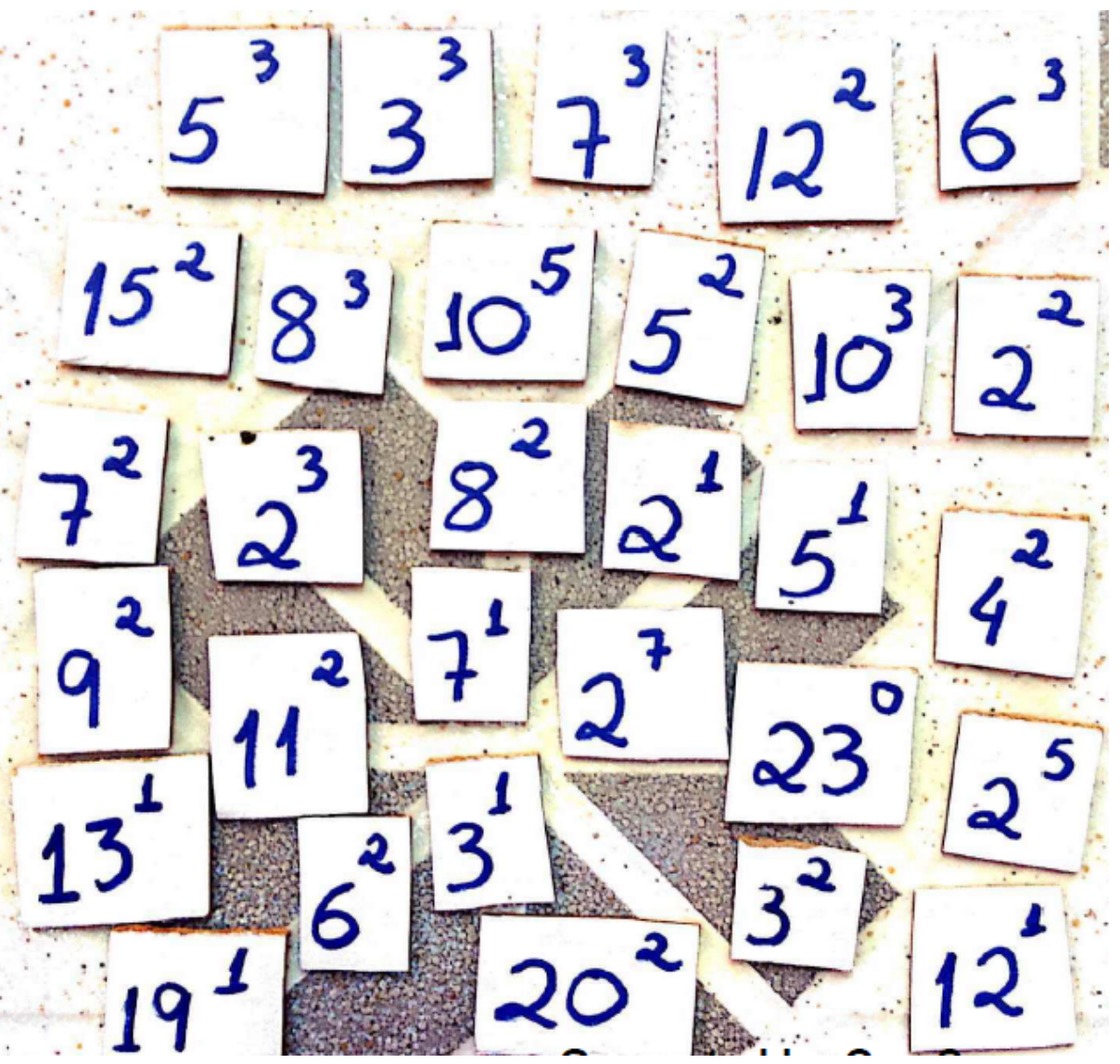

Figura 1. Peças sorteadas.

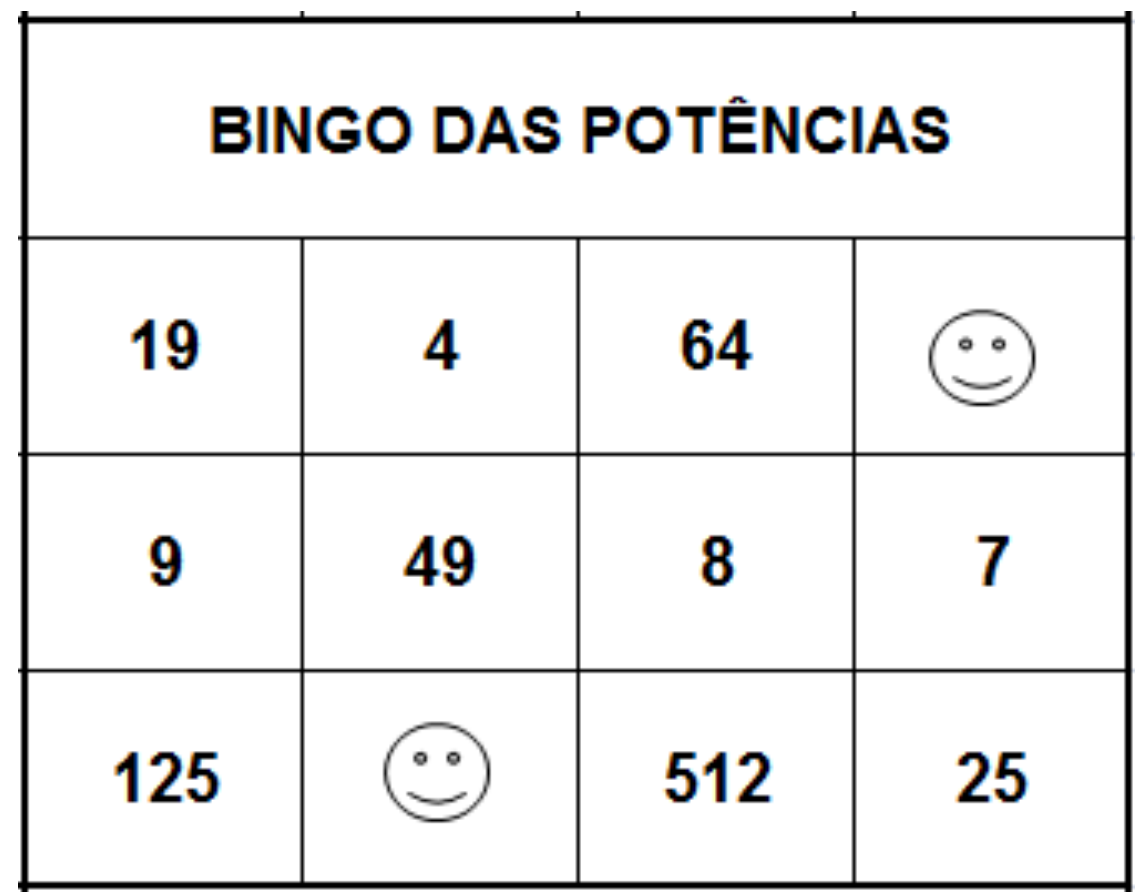

Figura 2. Exemplo de uma cartela do jogo pedagógico de bingo. 
$\mathrm{Na}$ oficina dos jogos do baralho das potências e expressões numéricas foram trabalhadas as propriedades do produto e divisão de potências de mesma base, potência de uma potência e da potência de um produto. Cada carta do baralho com uma expressão tinha uma respectiva carta com seu resultado conforme Figura 3.

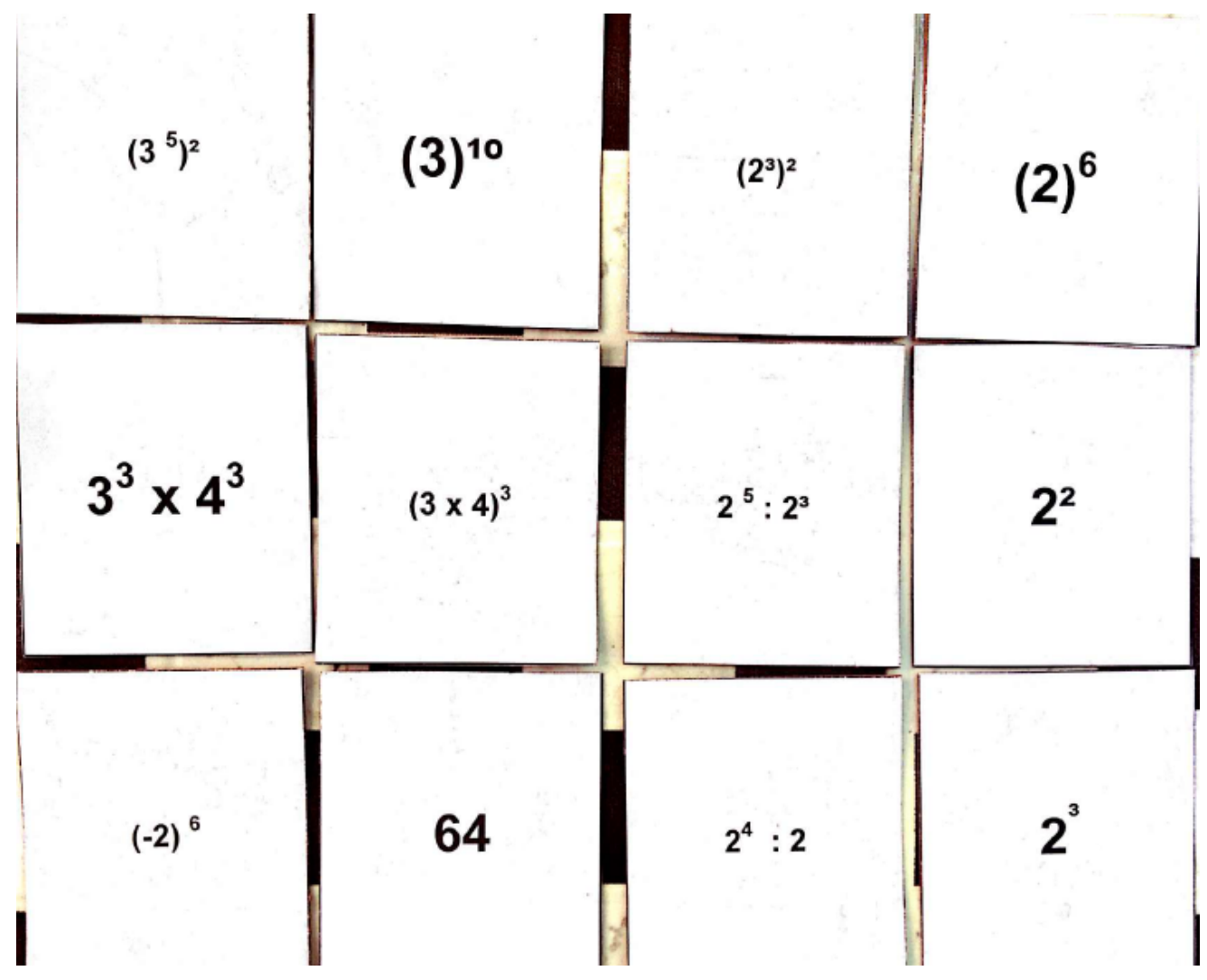

Figura 3. Exemplo de cartelas do baralho da potenciação.

O interessante desta oficina é que quando os alunos se deparavam com alguma carta e não tinham certeza sobre a propriedade a ser utilizada, eles consultavam o próprio caderno para tirar as dúvidas e assim prosseguir na jogada. Desta forma percebi que a revisão dos conteúdos estava ocorrendo de uma forma diferente, porém de forma eficaz. A utilização do caderno como auxilio foi muito importante, pois os alunos de certa forma resolveram vários exercícios sobre o conteúdo da prova e muitos nem se deram conta de que estavam revisando e aplicando o conteúdo ao mesmo tempo. 0 recurso do caderno foi mais presente na atividade do baralho das expressões numéricas, pois nesta atividade eles precisavam resolver uma pequena expressão numérica e depois encontrar seu respectivo resultado, conforme exemplo mostrado nas cartelas na Figura 4. 


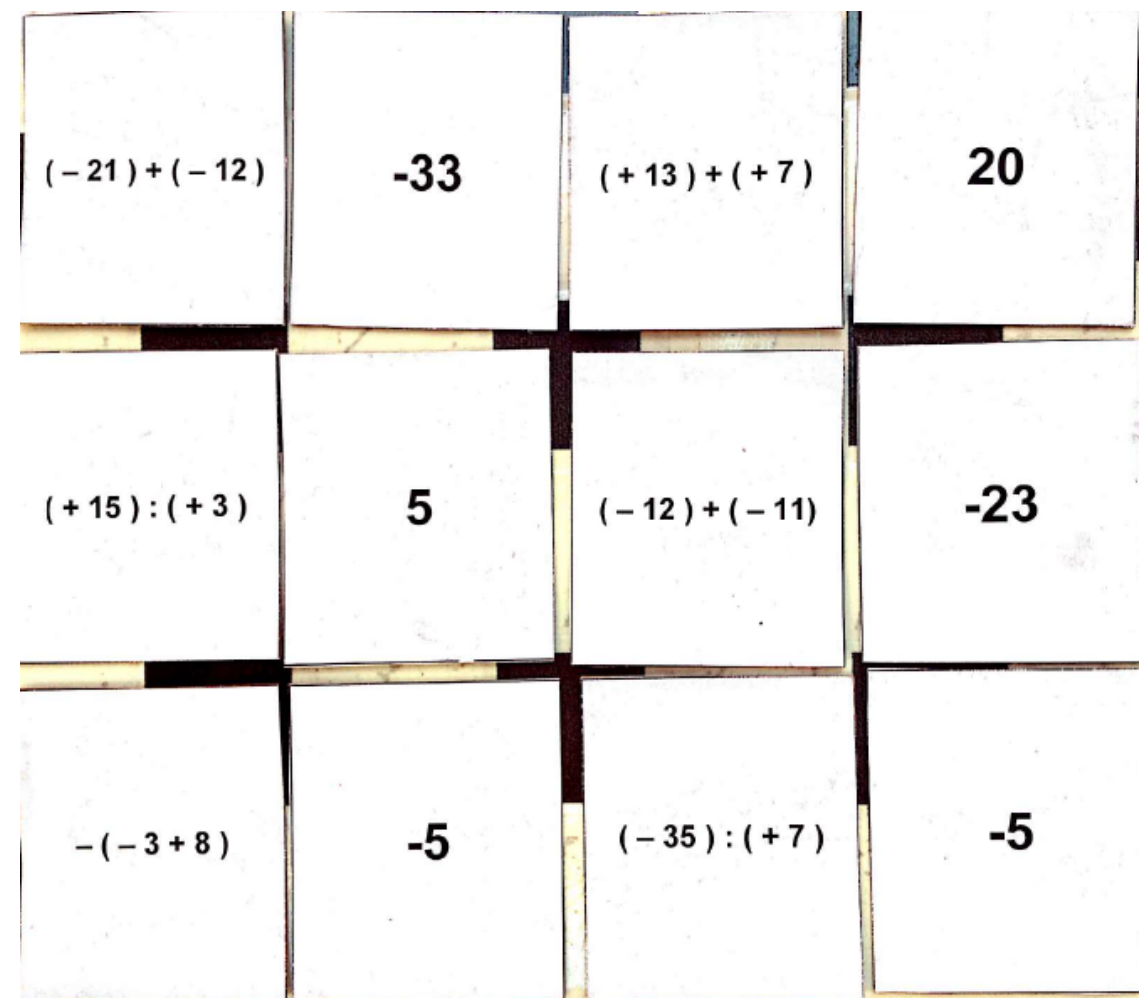

Figura 4. Exemplo de cartelas do baralho das expressões numéricas.

Um fato interessante que verifiquei nesta atividade foi a ajuda que as duplas adversárias se davam. Independente do jogo os alunos buscavam acertar o resultado das expressões, pois caso alguma dupla errasse algum cálculo eles não poderiam terminar o jogo, uma vez que, alguma carta iria ficar sem o seu par. Ao final da realização das oficinas fiz uma reflexão sobre todas as atividades realizadas e vi que os objetivos que eu tinha com cada uma foram alcançados e, além disso, vi que outras ações foram tomadas pelos alunos como usar o caderno para auxiliar na resolução das atividades.

A oficina do bingo da potenciação foi a de maior sucesso entre os alunos e, segundo relatos dos mesmos, o sucesso desta atividade ocorreu porque toda a turma participou de forma conjunta e integrada. 0 vencedor desta atividade foi um aluno que possui certa dificuldade com a matemática; este fato me deixou muito feliz, pois vi que minha atividade atingiu não só os alunos com facilidade, mas também os alunos com dificuldades. Percebi que uma aula de cinquenta minutos foi suficiente para realizar o bingo e depois o jogo da memória; ao todo as atividades duraram 40 minutos e nos 10 minutos restantes eu fiz a chamada e discuti os jogos a serem aplicados no segundo dia de oficinas. As atividades do baralho e jogo da memória também tiveram pontos importantes a considerar. 
No jogo do baralho percebi que os alunos tiveram um pouco de dificuldades no inicio, pelo fato desta atividade trabalhar com as propriedades da potenciação, porém este jogo foi o que mais estimulou os alunos a consultar o material didático a procura da resposta correta. Alguns alunos reclamaram da dificuldade de brincar com o baralho, desta forma, eu fiz uma reorganização dos mesmos e procurei formar as duplas colocando alunos com mais dificuldades ao lado de alunos com facilidades com o objetivo dos alunos ajudarem uns aos outros. Em relação à atividade do jogo da memória os alunos apresentaram mais dificuldades com as regras próprias do jogo da memória do que com os conteúdos específicos. Este foi um jogo mais descontraído, pois os alunos não tinham adversários e, desta forma, buscavam acertar para obter o maior número de pontos.

O segundo dia de oficinas durou cerca de 30 minutos. 0 restante do tempo foi utilizado para sanar algumas dúvidas que ainda persistiam em relação aos jogos realizados e também para fazermos uma reflexão sobre as atividades realizadas. Os alunos gostaram muito das oficinas e pediram para elas serem realizas mais vezes. Eu fiz uma pequena pesquisa no final da aula e perguntei qual o jogo que eles mais gostaram. A maioria dos alunos respondeu o bingo da potenciação, em seguida o jogo da memória e por fim o jogo do baralho da potenciação. Acredito que o baralho foi o menos citado por apresentar um grau de dificuldade maior. Ao final das oficinas eu pedi que os alunos colassem as cartelas do bingo nos cadernos para que eu fizesse a posterior avaliação da participação. $\mathrm{Na}$ aula seguinte a realização das oficinas foi aplicada a avaliação trimestral. A prova valia cinco pontos e abordava o conteúdo de potenciação. Na Tabela 1 estão apresentadas as médias das notas obtidas pelos alunos e em seguida uma análise dos resultados obtidos.

Tabela 1. Desempenho dos alunos na avaliação trimestral.

\begin{tabular}{l|c|c|c|c|c|c}
\hline \multicolumn{7}{|c}{ DESEMPENHO DOS ALUNOS NA AVALIAÇÃO TRIMESTRAL } \\
\hline DESEMPENHO & RUIM & REGULAR & BOM & MUITO BOM & EXCELENTE & TOTAL \\
\hline QUANTIDADE DE ALUNOS & 2 & 3 & 12 & 6 & 2 & 25 ALUNOS \\
\hline PERCENTUAL DE ALUNOS & $8 \%$ & $12 \%$ & $48 \%$ & $24 \%$ & $8 \%$ & $100 \%$ \\
\hline
\end{tabular}

Após a avaliação trimestral fiz uma análise dos resultados e verifiquei que dos vinte e cinco alunos da turma, 8\% ficaram com notas abaixo da média, 12\% ficaram com notas na média igual a 2,5 pontos, $48 \%$ ficaram com notas boas, entre três e quatro pontos, 24 \% ficaram com 
notas entre quatro e quatro pontos e meio e $8 \%$ da turma ficou com nota máxima. Verificando estas notas percebemos que a maior parte dos alunos ficou com notas acima da média trimestral que é 2,5 pontos.

Esse resultado verificado através da prova de certa forma serviu de avaliação para às oficinas realizadas, uma vez que, estas fizeram parte das aulas destinadas ao trabalho com o conteúdo de potenciação. E o aspecto mais importante foi saber que a oficina atingiu alunos que até então apresentavam certa aversão à matemática. Isso com certeza possibilitará um melhor trabalho com as futuras disciplinas matemáticas. Apesar de ter utilizado duas aulas para fazer as oficinas vejo que é possível realizar mais vezes estas atividades, porém é preciso um planejamento de quais atividades serão utilizadas e o objetivo de cada uma, de forma a trabalhar os jogos correlacionados com os conteúdos afins.

\section{CONSIDERAÇÕES FINAIS}

Com esta experiência cheguei à conclusão de que é possível trabalhar os conteúdos matemáticos com o auxilio de jogos como recursos pedagógicos para o ensino e aprendizagem de matemática, especificamente, nas aulas revisão de conteúdos. 0 resultado obtido com as atividades foi satisfatório se comparado com outras avaliações aplicadas sem o auxílio destas oficinas. 0 resultado alcançado em relação ao envolvimento e empolgação dos alunos também foi realizador, uma vez que, de certa forma consegui mostrar para eles que é possível "brincar com a matemática" e isso me deixou muito feliz. Em suma, os resultados alcançados foram muito satisfatórios e com certeza aplicarei estas atividades em outras turmas e farei também adaptações destas oficinas a outros conteúdos, com o objetivo de conseguir aplicar em outras séries.

\section{REFERÊNCIAS}

D'AMBRÓSIO, Ubiratan. Educação Matemática: da teoria a prática. Campinas, SP: Papirus, 2011.

PIAGET, J. A linguagem e o pensamento da criança. Rio de Janeiro: Fundo de Cultura, 1984. ROSA NETO, Ernesto. Didática da matemática. 4aㅡ ed. São Paulo: Ática, 1992.

REGO, T. C. Vygotsky: uma perspectiva histórica - cultural da educação. Editora Vozes: Petrópolis, 2000. 